\title{
THE BLURRING COPYRIGHT-PATENT PARADIGM: IDEA-EXPRESSION DICHOTOMY
}

\section{CHINMAYA KUMAR MOHAPATRA \& AMRITA MISHRA}

Assistant Professor, Faculty of Legal Studies, Siksha O Anusandhan (Deemed to be University), Bhubaneswar, Odisha, India

ABSTRACT
There is scarcely any single theory of copyright law which is more fundamental or replicated more frequently than the
so-called dichotomy of idea-expression. It has been opposed by some scholars who have researched the dichotomy in
the greatest depth, arguing that continued perception of dichotomy is neither warranted nor beneficial in case-
decision. However, in hundreds of cases, the theory established by common law procedures was pursued by courts
who applied it to address relevant copyright problems, which over the years has led to vagueness and ambiguity. The
United Kingdom (UK) Supreme Court (SC) ruling in Lucas film vinsworth has compounded the uncertainty about
the requirements and expectations for its operation Because the doctrine's primary aim is to explicitly identify what
should be covered by copyright, what belongs to the public domain, and what is shielded by patent law, rulings
concerning dichotomy may therefore have a substantial effect on the patent copyright framework. This paper would
explore the reasoning behind the Lucas film decision and its effect on the presentation of the notion of dichotomy and
copyright patent interrelationship to decide whether it has produced significant determinations in the structure and
nature of the copyright law itself.
KEYWORDS: Copyright, Idea-Expression Dichotomy, Patent

Received: Jun 08, 2020; Accepted: Jun 28, 2020; Published: Aug 26, 2020; Paper Id.: IJMPERDJUN2020898

\section{INTRODUCTION}

One of the copyright law's most basic tenets is this dichotomy that "there is no copyright in an idea, copyright only subsists in its expression."6 Copyright does not cover ideas, but it offers security for the manner the concept or knowledge is conveyed, e.g. in literature, painting, moving picture. An engineer, for instance, finds a cold-fusion technique. When the author was to write a description of the mechanism down on paper, the description would be protected by copyright. No one will be allowed to copy his work, but anyone reading his article will be free to carry out the operation without risk of copyright infringement, because the operation itself — the idea — is not covered by copyright. Protection refers to patent law. Courts consider this dichotomy as the basic axiom of copyright law to be used in deciding what is protected in cases of infringement. ${ }^{1}$

The common law theory can be traced back to the US decision in Baker v Selden, where it was held that copyright subsisting in a book describing a record-keeping system did not apply to cover the process described and explained because it was open to all to use. Herschell LC pointed to the "fallacy committed by lawyers that copyright could only subsist in an image" in the UK case of Hollinrake v. Truswell. Yet the "fallacy" persists till now. It was later articulated in University of London Press v University Tutorial Press by Petersen J. On this basis can be clarified Walter v Lane. The speech by Lord Roseberry was the idea, but it was the Times writer who gave

\footnotetext{
${ }^{1}$ Siva Vaidhanathan, Copyrights and Copywrongs( New York University Press 2001). 
it particularity of expression. The House of Lords acknowledged the use of dichotomy in LB (Plastics) Ltd v Swish Goods Ltd where the defendants used the idea of the plaintiffs to make a similar drawer protected by the copyright of the plaintiff. Copyright law has explicitly only covered particular manifestations of ideas, but it has provided free reign for ideas itself. Lord Hoffmann found in Designers Guild v. Russell William Ltd that copyright rights applies only to inventions that are condensed into a content form. ${ }^{2}$

\section{DISCUSSIONS}

\section{Test for the Dichotomy}

The idea / concept dichotomy is crucial in deciding if anyone has taken more than a de minimis sum of the protected speech of an artist. 'Many of the early copyright lawsuits are only shielded against actual copying, not from a more abstract taking of a copyrighted text. The central sense is form, as structure is basically covered by copyright. Examples include Erle J's dictum in Jefferys v. Boosey 'the value of property is in the order of terms in the text of the author; not in the terms themselves, nor in the ideas conveyed by those words' and in Holmes v. Hurst, U.S. Supreme Court. 'The right to the arrangement of words which the creator has chosen to convey his thoughts.' At the practical level, violation will consist of an accurate duplication of the entire or section of these particular features: the arrangement of words for literary works; exact word arrangements for artistic works. use of lines, colours and textures; for musical works a certain combination and sequence of notes, rhythms and silence. Infringement can occur by copying words or not verbatim. Although infringement includes exact similarities between works of the former category, infringement in the latter category requires significant similarities between works. The idea / expression dichotomy arises more in the nonverbatim context where the main question is whether the pieces found were a significant part of work. The definition of a "significant component" is more contextual than quantitative, and it has been called significant for a very small portion of a work. Of which the major part of the theory remains ambiguous. A single stanza of a poem of one hundred stanzas may be the only one worth reading, and may reflect all the talents and work worth taking on by an poet. ${ }^{3}$ Also important is physical labor and ability, but not the deciding factor. Consequently a secretary who brings down a dictation of notes or a pure copyist is not an author and does not get any defense. Even in a case where the defendants actually saw one of the goods of the complainant and created a version themselves, it was held that there was no infringement as ability and labour It admits that it can be very difficult to differentiate between , idea "and „expression." Learned Hand said that no one (between idea and expression) has ever been able to overcome the barrier, and no one will ever. There is another standard called the "merger test" which, while highly dubious in the UK, claims that if there is no other way to communicate a certain concept, there would be no protectible copyright.

\section{Justification for the Doctrine}

The rationale for defending words but not ideas lies in balancing society's needs in the free exchange of ideas and knowledge against writers 'property rights, and in preventing inequality to the rest of the world It delineates the limits of the copyright monopoly, encourages freedom of speech and the growth of information and culture, increases the creative use of copyright works, helps to address serious infringing problems and stimulates innovation in the copyright sector It delineates the boundaries of the copyright monopoly, encourages freedom of expression and the development of knowledge and culture, improves the innovative use of copyright works, helps to resolve significant infringement issues

\footnotetext{
${ }^{2}$ Peter Groves, Intellectual Property Law in a Box: Study Pack (SemplePiggotRochez 2006).

${ }^{3}$ World Intellectual Property Organisation Copyright Treaty 1996.
} 
and boosts creativity in the UK's originality level copyright market, restricts fair trade protections and the deleterious impact of the Digital Society. The problems around derivative phrases caused Sir Andrew Gowers and Ian Hargreaves to propose that exceptions to copyright infringement be made for constitutional satire, pastiche and transformational use. ${ }^{4}$

\section{Weakness of the Doctrine}

The fundamental issue with the dichotomy is that, when comparing ideas to words, the courts and analysts rarely describe or explain what precisely they mean by the phrases "idea" and "speech," it is impossible to draw the distinction between protected speech and unprotected ideas.No litmus research. As Judge Learned Hand said, "Obviously, where an imitator has gone beyond copying the" idea "and copied the" speech, "no theory can be mentioned. Accordingly, decisions will necessarily be ad hoc. Sometimes the challenge of formulating a simple distinction between ideas and manifestations of ideas is a consequence of the intellectual inability of conceiving expresseless ideas. No "expressionless thought" exists and it makes no sense to talk of an idealless word, at least in any substantive prose. So the dichotomy remains in the vagueness of extremes. As Lord Hoffmann said, "everything depends on what you mean by 'ideas.' The problem is compounded by judicial refusal to allow unlawful interference with the pecuniary benefits of possession of copyright in situations where consumers are allowed to use ideas and expressions of ideas in an original work.

\section{The Lucasfilm Case}

But what does dichotomy mean? Throughout the twentieth century, the dichotomy has weakened in reality and most certainly, as this judgment suggests, it will continue to become "hard to describe, harder to recognize, and thus harder to protect." If the final version had been accepted by Lucasfilm, he made helms for use in the script. He began selling the helmets from his website all over the world after thirty years like USA. Lucasfilm successfully prosecuted him for violation of copyright in the US and then challenged the UK court for infringement of copyright and the enforcement of the US judgment. The question arose in the process, if the helmet was a sculpture. First Instance Tribunal i.e. High Court (HC) ruled, eventually affirmed by the Court of Appeal (CA) and SC, that it was not a sculpture and thus did not entail any infringement under UK law. The CA relied heavily on the HC decision when describing sculpture and the SC affirmed the decision on this point.

HC's Mann J sets nine criteria to better decide whether an object is a sculpture.

- Normal use of the word "sculpture" must be taken into account.

- It could go beyond ordinary meaning in the sense of a work in art gallery.

- It would be improper to stray too far from its normal meaning.

- No judgment may be made about artistic merit.

- Not every three dimensional representation is a sculpture.

- It has "visual appeal" as part of its purpose.

- It may have any additional use.

- The purpose of creation must be considered.

- The process of fabrication is relevant but not determinative.

\footnotetext{
${ }^{4}$ Donaghue v. Allied Newspapers [1938] Ch 106 at 110.
} 
The SC focused on "the multi-factor solution" It is argued that much of the logic in court is traditionally biased. The SC stressed the establishment of three different levels of phased protection in the UK Parliamentary history: copyright, licensed design rights and unregistered design rights. While creative pieces of art like sculpture have the fullest security, then pieces of eye appeal and then a limited degree of safety to solely practical artifacts under the unregistered scheme of design correctness. There are legitimate policy explanations for the disparity in the enforcement period, and the court does not allow the limits of complete copyright rights to crawl outward. "Thus, taking into account the helmet's historical history and practical purpose, the SC upheld HC and CA's decision. ${ }^{5}$

\section{Further Erosion of the Dichotomy by Lucasfilm}

At the heart of the case decision was the question: should all three-dimensional and industrially created three-dimensional art information be treated as copyrightable creative objects or should such a work actually pursue the protection of sui generis architecture. In Wham-O, the flying Frisbees kept sculpture as "a sculpture will in any manner represent the sculptor's concept in a three-dimensional shape." But the Lucasfilm ruling dismissed the notion that the representation of a concept would be covered by copyright and placed considerable focus on the intent of creating the object. Yet again it has defined only certain limiting factors for protectable expression in terms of sculpture's creative works. Which would be the criterion for such distinction, if any, from protectable works in the other: literature, theatrical, musical and other works of art, sound recordings, broadcasts, films, etc.? Interestingly, in all of the three courts 'rulings, the interpretation "idea interpretation dichotomy" never existed. Yet by putting weight on the antagonistic rule that the resulting dichotomy would be between only two forms: protected and unprotected speech, not between unprotected concept and protected speech. It has put tremendous emphasis on conventional dichotomy. First, the decision went beyond the fundamental premises of dichotomy and instead brought more doubt to the applicable decision-making process by eroding its applicability as a key axiom in the resolution of violation cases.

It has put tremendous emphasis on conventional dichotomy. First, the decision went beyond the fundamental premises of dichotomy and instead brought more doubt to the applicable decision-making process by eroding its applicability as a key axiom in the resolution of violation cases. If applied, any eligible creative creation will enjoy the full scope of protection of copyright- the creator's lifetime plus 70 years. A six-week "Call for Proof" was also introduced on the timing of the repeal. The reform will potentially have the copyright law back on track. ${ }^{6}$

\section{CONCLUSIONS}

For more than a century the principle of the term dichotomy has acted as an important axiom in copyright law. While it has been blamed for its vagueness and failure to draw a distinction between "idea" and "speech," it has been used in violation cases almost daily by courts. The central concept of liberating the idea for the Commons while preserving the development of the author has earned a lot of accolade. Yet ad hoc and inconsistent assumptions have raised doubts about their authority and plunged their destiny into doubt. Adding to the confusion and diffidence was the Lucasfilm decision. It acknowledged the storm troopers helmet's "creative existence," but on the ground of lack of artistic intent it refused safety. Instead of the conventional concept speech model, the case distinguished between protectable and unprotectable speech while challenging the fundamental tenets of the dichotomy. This greatly undermined the efficacy of the dichotomy and directly

\footnotetext{
${ }^{5}$ Total Information Processing Systems Ltd v Daman Ltd [1992] FSR 171; Frybarger v International Business Mach Corp, 812 F2d 525, 530 (9th Cir 1987)

${ }^{6}$ Designers Guild Ltd v Russell Williams (Textiles) Ltd [2001] FSR 113.
} 
affected the process of copyright protection. This has also distorted the delicate definition of copyright licenses in terms of ensuring protection for creative works. The whole IP system has been feeling the effect. Accordingly, the UK Government has taken regulatory reforms steps to bring the framework back on track. But what does dichotomy mean? Throughout the twentieth century, the dichotomy has weakened in reality and most certainly, as this judgment suggests, it will continue to become "hard to describe, harder to recognize, and thus harder to protect.

\section{REFERENCES}

1. Karim, Md. "The Idea/Expression Dichotomy and Its Impact on the Blurring Copyright-Patent Paradigm." The Idea/Expression Dichotomy and Its Impact on the Blurring Copyright-Patent Paradigm (January 20, 2014) (2014).

2. Reichman, Jerome H. "Charting the collapse of the patent-copyright dichotomy: Premises for a restructured international intellectual property system." Cardozo Arts \& Ent. LJ 13 (1994): 475.

3. Carrier, Michael A. "Cabining intellectual property through a property paradigm." Duke LJ 54 (2004): 1. 
